\title{
Chapter 9 \\ The Nucleocapsid Protein of the SARS \\ Coronavirus: Structure, Function \\ and Therapeutic Potential
}

\author{
Milan Surjit and Sunil K. Lal
}

\begin{abstract}
As in other coronaviruses, the nucleocapsid protein is one of the core components of the SARS coronavirus $(\mathrm{CoV})$. It oligomerizes to form a closed capsule, inside which the genomic RNA is securely stored thus providing the SARS-CoV genome with its first line of defense from the harsh conditions of the host environment and aiding in replication and propagation of the virus. In addition to this function, several reports have suggested that the SARS-CoV nucleocapsid protein modulates various host cellular processes, so as to make the internal milieu of the host more conducive for survival of the virus. This article will analyze and discuss the available literature regarding these different properties of the nucleocapsid protein. Towards the end of the article, we will also discuss some recent reports regarding the possible clinically relevant use of the nucleocapsid protein, as a candidate diagnostic tool and vaccine against SARS-CoV infection.
\end{abstract}

\subsection{Introduction}

By definition, nucleocapsid is a viral protein coat that surrounds the genome (either DNA or RNA). Nucleocapsid protein is the major constituent of a viral nucleocapsid. It is capable of associating with itself and with the genome, thus packaging the genome inside a closed cavity. In some viruses, nucleocapsid protein may also be assisted by other viral cofactors to form the capsid. However, in coronaviruses (including SARS-CoV), the nucleocapsid protein alone is capable of forming the capsid. The primary advantage of the virus for encoding the nucleocapsid protein is that the latter encloses and protects the viral genome from coming into direct contact with the harsh environment in the host. In fact, in some simple viruses

\footnotetext{
S.K. Lal $(\bowtie)$

Virology Group, ICGEB, P. O. Box: 10504, Aruna Asaf Ali Road, New Delhi 110067, India e-mail: sunillal@icgeb.res.in
} 
like hepatitis $\mathrm{E}$ virus and polio virus, the nucleocapsid protein is the only coat that protects the genome from the outside world. However, in complex viruses, like hepatitis B virus and coronaviruses (including SARS-CoV), the nucleocapsid is covered by an additional coat composed of other viral proteins (spike protein is a major component of this coat). Besides this property, nucleocapsid proteins of several viruses have been demonstrated to play multiple regulatory roles during viral pathogenesis. They are equipped with specific structural motifs and/or signature sequences, by which they associate with other viral/ host factors and skew the host cellular machinery in such a manner that it becomes more favorable for the survival of the virus. Nucleocapsid protein is also one of the most abundantly expressed viral proteins and it is the major antigen recognized by convalescent antisera. Hence, it is tempting to evaluate its potential as a candidate diagnostic tool or vaccine against the virus.

Therefore, understanding the properties of the nucleocapsid protein is of utmost importance to any virologist in order to understand the biology of the virus and develop effective tools to control the infection. Since the identification and isolation of SARS-CoV in 2003, several laboratories around the world have focussed their research on characterization of various properties of the nucleocapsid protein. An indirect measure of the curiosity among SARS-CoV researchers to study the nucleocapsid protein is revealed from the fact that in PubMed the number of SARS-CoV research publications focussed on nucleocapsid protein is second only to those on spike protein. Evidence accumulated from these articles has helped us gain substantial understanding of the properties of this protein. In this article, we will provide a comprehensive description of all the different properties of the nucleocapsid protein, as established by independent workers from several laboratories. We will conclude this article with the discussion of some of the remaining challenges in this field that need to be addressed in future.

\subsection{N-Protein: Structure and Composition}

The nucleocapsid $(\mathrm{N})$ protein is encoded by the ninth ORF of SARS-CoV. The same ORF also codes for another unique accessory protein called ORF9b, though in a different reading frame, whose function is yet to be defined. The N-protein is a 46-kDa protein composed of 422 amino acids (Rota et al. 2003). Its N-terminal region consists mostly of positively charged amino acids, which are responsible for RNA binding. A lysine-rich region is present between amino acids 373 and 390 at the C-terminus, which is predicted to be the nuclear localization signal. Besides these, an SR-rich motif is present in the middle region encompassing amino acids 177-207. Biophysical studies done by Chang et al. (2006) have suggested that this protein is composed of two independent structural domains and a linker region. The first domain is present at the N-terminus, inside the putative RNA binding domain, and the second domain consists of the C-terminal region that is capable of selfassociation. Between these two structural domains, there lies a highly disordered 


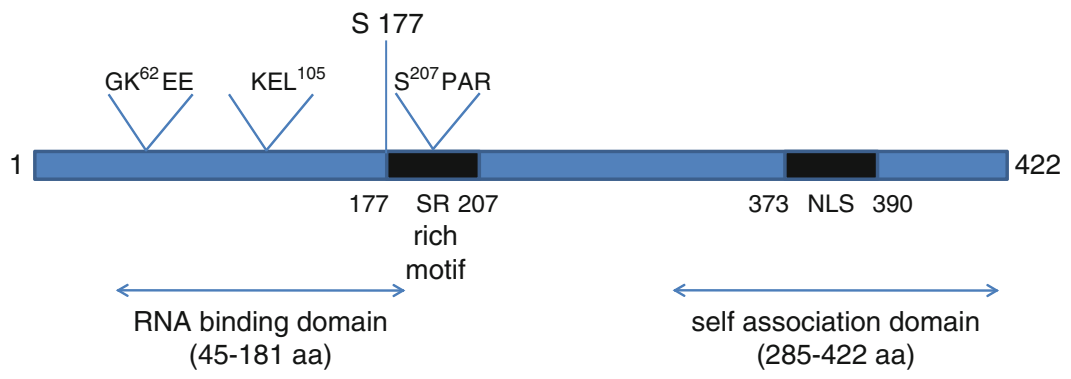

Fig. 9.1 Structure of the SARS-CoV nucleocapsid protein. A schematic diagram showing different domains identified to date. The numbers 1-422 correspond to the length in amino acids of the $N$ gene. GKEE represents the sumoylation motif (lysine residue). KEL is the RXL motif, responsible for binding with cyclin D, and SPAR is the motif that gets phosphorylated by the cyclin-CDK complex (serine residue). S177 is the serine 177 residue that gets phosphorylated by GSK3

region, which serves as a linker. This region has been reported to interact with the membrane (M) protein and human cellular hnRNPA1 protein (Fang et al. 2006; Luo et al. 2005). Besides, this region is also predicted to be a hot spot for phosphorylation. Hence, in summary, the N-protein can be classified into three distinct regions (Fig. 9.1), which may serve completely different functions during different stages of the viral life-cycle. A similar mode of organization has been reported for other coronavirus nucleocapsid proteins.

\subsection{Stability of the N-Protein}

In-vitro thermodynamic studies done by Luo et al. (2004b) using purified recombinant $\mathrm{N}$-protein have shown it to be stable between $\mathrm{pH} 7$ and 10, with maximum conformational stability near $\mathrm{pH}$ 9. Further, it was observed to undergo irreversible thermal-induced denaturation. It starts to unfold at $35^{\circ} \mathrm{C}$ and is completely denatured at $55^{\circ} \mathrm{C}$ (Wang et al. 2004). However, denaturation of the N-protein induced by chemicals such as urea or guanidium chloride is a reversible process.

\subsection{Posttranslational Modification}

As in other coronavirus N-proteins, SARS-CoV N-protein has been predicted and later experimentally proven to undergo various posttranslational modifications such as acetylation, phosphorylation, and sumoylation.

Acetylation is the first modification of the $\mathrm{N}$-protein to be experimentally proven. By mass spectrometric analysis of convalescent sera from several SARS patients, it has been shown that the $\mathrm{N}$-terminal methionine of $\mathrm{N}$ is removed and all 
other methionines are oxidized and the resulting $\mathrm{N}$-terminal serine is acetylated. However, the functional relevance of this modification, if any, remains to be elucidated (Krokhin et al. 2003).

Another unique modification of the N-protein is its ability to become sumoylated. Studies done by Li et al. (2005a) have clearly established that heterologously expressed $\mathrm{N}$ in mammalian cells is sumoylated. Using a site-directed mutagenesis approach, the sumoylation motif has been mapped to the 62nd lysine residue, which is present in a putative sumo-modification domain $\left(\mathrm{GK}^{62} \mathrm{EE}\right)$. Their data further suggests that sumoylation may play a key role in modulating homo-oligomerization, nucleolar translocation and cell-cycle deregulatory property of the $\mathrm{N}$-protein. Further experimental support regarding sumoylation of N-protein came from another independent study carried out by Fan et al. (2006) wherein they have demonstrated an association between the N-protein and Hubc9, which is a ubiquitinconjugating enzyme of the sumoylation system. They have also mapped the interaction domain to the SR-rich motif, which is in agreement with the earlier report. However, they failed to detect the involvement of the GKEE motif in mediating this interaction (Fan et al. 2006).

Initially, the SARS-CoV N-protein was predicted to be heavily phosphorylated. Later on, from results obtained in our laboratory as well as by other researchers, it is now clear that the N-protein is a substrate of multiple cellular kinases. First experimental evidence for the phosphorylation status of the $\mathrm{N}$-protein came from the study done by Zakhartchouk et al. (2005) in which, using [ $\left.{ }^{32} \mathrm{P}\right]$ orthophosphate labelling, they were able to observe phosphorylation of adenovirus-vectorexpressed N-protein in 293T cells. Further studies done in our laboratory clearly confirmed this observation. The majority of the N-protein was found to be phosphorylated at its serine residues (although the involvement of threonine and tyrosine residues could not be detected; they may be occurring in vivo). In addition, using a variety of biochemical assays, it was proved that, at least in vitro, the $\mathrm{N}$-protein could become phosphorylated by mitogen-activated protein kinase (MAP kinase), cyclin-dependent kinase (CDK), glycogen synthase kinase 3 (GSK3), and casein kinase 2 (CK2). Also, this data provided preliminary indication regarding phosphorylation-dependent nucleo-cytoplasmic shuttling of the N-protein (Surjit et al. 2005). A recent report published by Wu et al. (2008) has further confirmed that $\mathrm{N}$-protein is a substrate of GSK3 enzyme, both in vitro and in vivo. Using a variety of biochemical and genetic assays, it was clearly demonstrated that serine 177 residue of N-protein was phosphorylated by GSK3. An antibody specific to phospho 177 residue of the N-protein could efficiently detect the phospho N-protein both in vitro and in SARS-CoV infected cells. Interestingly, biochemically mediated inhibition of GSK3 activity in SARS-CoV infected cells also leads to around $80 \%$ reduction in viral titer and subsequent induction of a virus-induced cytopathic effect. The authors proposed that GSK3 may be a major regulator of SARS-CoV replication, possibly by virtue of its ability to phosphorylate the N-protein. However, phosphorylation of other viral and/or host proteins by GSK3 may also be a determinant of the observed cytopathic effect. 


\subsection{Localization of the N-Protein}

In contrast to the $\mathrm{N}$-protein of many other coronaviruses, the SARS-CoV N-protein is predominantly distributed in the cytoplasm, when expressed heterologously or in infected cells (Surjit et al. 2005; You et al. 2005; Rowland et al. 2005). In infected cells, a few cells exhibited nucleolar localization (You et al. 2005). As reported by You et al. (2005), the N-protein contains pat4, pat7 and bipartite-type nuclear localization signals. It has also been predicted to possess a potential CRM-1dependent nuclear export signal. However, no clear experimental evidence could be obtained regarding the involvement of these signature sequences in regulating the localization of the N-protein. Interestingly, studies done in our laboratory revealed that the majority of N-protein localized to the nucleus in serum-starved cells. This phenomenon could be reproducibly observed both in biochemical fractionation as well as immunofluorescence studies. In addition, treatment of cells with specific inhibitors of different cellular kinases such as CK2 inhibitor and CDK inhibitor resulted in retention of a fraction of the N-protein in the nucleus, whereas GSK3 and MAPK inhibitor had very little effect. Further, N-protein was found to be efficiently phosphorylated by the cyclin-CDK complex, which is known to be active only in the nucleus. The N-protein was also found to associate with 14-3-3 protein in a phospho-specific manner and inhibition of the 14-3-30 protein level by siRNA resulted in nuclear accumulation of the $\mathrm{N}$-protein. Although these experiments are too preliminary to conclusively provide any answer regarding the intracellular localization of N-protein, nevertheless they do provide substantial clues regarding the physical presence of the N-protein in the nucleus, under certain circumstances, which may be a very dynamic phenomenon. Another study done by Timani et al. (2005) using different deletion mutants of the N-protein fused to EGFP showed that the N-terminal of N-protein, which contains the NLS 1 (aa 38-44), localizes to the nucleus, whereas the C-terminal region containing both NLS 2 (aa 257-265) and NLS 3 (aa 369-390) localizes to the cytoplasm and nucleolus. Using a combination of different deletion mutants, they concluded that the N-protein may act as a shuttle protein between cytoplasm-nucleus and nucleolus. Taken together, all these results further suggest that the N-protein per se has the physical ability to localize to the nucleus. Whether this localization is regulated through phosphorylation-mediated activation of a potential NLS or piggy-backing by association with another cellular nuclear protein or through any other mechanism remains to be established.

\subsection{Genome Encapsidation: Primary Function of a Viral Capsid Protein}

Being the capsid protein, the primary function of the N-protein is to package the genomic RNA in a protective covering. In order to achieve this structure, the $\mathrm{N}$-protein must be equipped with two different characteristic properties; such as 
(1) being able to recognize the genomic RNA and associate with it, and (2) selfassociate into an oligomer to form the capsid. The N-protein of SARS-CoV has been experimentally proven to possess these properties in vitro, as discussed below.

\subsubsection{Recognition and Binding with the Genomic RNA}

The first experimental evidence regarding the RNA binding property of the N-protein came from the work of Huang et al. (2004), in which, by NMR studies, they proved the ability of the N-terminal domain to associate with several viral $3^{\prime}$ untranslated RNA sequences. Additionally, Chen et al. (2007) reported the presence of another RNA binding domain at the C-terminal region (residues 248-365) of the $\mathrm{N}$-protein, which was proposed to be a stronger interaction than that at the $\mathrm{N}$ terminus. Based on structural analysis of the RNA-protein interaction, they have further suggested that the genomic RNA is packaged in a helical manner by the N-protein. In another report published by Luo et al. (2006), the RNA binding motif of the N-protein was mapped to amino acid residues 363-382. In summary, the RNA binding ability of the $\mathrm{N}$-protein was attributed to its two distinct structural domains: the N-terminal domain (residues 45-181) and the C-terminal dimerization domain (residues 248-365). These two domains are spatially separated by long stretches of disordered region. A recent study done by Chang et al. (2008) has demonstrated RNA binding ability of these disordered regions. They have proposed that different RNA binding domains of the N-protein may cooperate to enhance the overall RNA binding efficiency of the N-protein and may also serve as interaction hubs for the association of $\mathrm{N}$-protein with other viral and/or host nucleic acid and/or proteins.

Perhaps the most convincing proof to date regarding the ability of the N-protein to package the genomic RNA came from the work of Hsieh et al. (2005). They have established a system to produce SARS-CoV VLPs by cotransfection of spike, membrane, and envelope and nucleocapsid cDNAs into Vero E6 cells. While testing the packaging of an RNA-bearing GFP fused to SARS-CoV packaging signal into this particle, they observed that presence of the N-protein is an absolute requirement. However, the $\mathrm{N}$-protein was not essential for the assembly of the empty particle per se. Further, by performing a filter binding assay using recombinant $\mathrm{N}$-protein, they were able to identify two independent RNA binding domains in the $\mathrm{N}$-protein; one at the $\mathrm{N}$ terminus (aa 1-235) and the other at the $\mathrm{C}$ terminus (aa 236-384). These results are in agreement with previous findings and further suggest that these two regions may be functional in vivo. Future experiments using a model infection system will confirm these observations.

\subsubsection{Formation of the Capsid}

One of the most crucial properties required by the N-protein for genome encapsidation is its ability to self-associate. Therefore, many laboratories have focused on 
characterizing this phenomenon, with an eye on developing possible interference strategies that may help in limiting virus propagation.

Initial studies done in our laboratory using a yeast two-hybrid assay revealed that $\mathrm{N}$-protein is able to self-associate through its C-terminal amino acid 209 residues (Surjit et al. 2004a). A parallel study done by He et al. (2004) using the mammalian two-hybrid system and sucrose gradient fractionation also proved the ability of the $\mathrm{N}$-protein to self-associate to form an oligomer. They further mapped the interaction region to amino acid 184-196 residues, encompassing the SR-rich motif. However, there were some discrepancies regarding the interaction domain mapped in these two studies. Later on, extensive biophysical and biochemical analysis done by Chen's laboratory (Yu et al. 2005, 2006) and Jiang's laboratory (Luo et al. 2006, 2005) have enriched our understanding of the oligomerization process of the Nprotein. In summary, the SR-rich motif does possess binding affinity, but this is specific for the central region (aa 211-290) of another molecule of N-protein, instead of the SR-rich motif itself. The C-terminal region (aa 283-422) possesses binding affinity for itself and to associate into a dimer, trimer, tetramer or hexamer, in a concentration-dependent manner. The essential sequence for oligomerization of the N-protein was identified to be residues 343-402. Interestingly, this region also encompasses the RNA binding motif of the N-protein, which prompts us to speculate that there might be mutual interplay between RNA binding and oligomerization activities of the N-protein. Further, the oligomerization was observed to be independent of electrostatic interactions and addition of single strand DNA to the reaction mixture containing tetramers of the $\mathrm{N}$-protein promoted oligomerization. Thus, it has been proposed that once the tetramer is formed by protein-protein interaction between nucleocapsid molecules, binding with genomic RNA prompts further assembly of the complete nucleocapsid structure.

\subsection{Perturbation of Host Cellular Process by the N-Protein}

Besides being the capsid protein of the virus, the N-protein of many coronaviruses is known to double up as a regulatory protein. The N-protein of the SARS-CoV too has been shown to modulate the host cellular machinery in vitro, thereby indicating its possible regulatory role during its viral life-cycle. Some of the major cellular processes perturbed by heterologous expression of the $\mathrm{N}$-protein are discussed below.

\subsubsection{Deregulation of Host Cell Cycle}

Three different groups have reported the ability of the N-protein to interfere with the host cell cycle in vitro. Work done by Li et al. (2005a, 2005b) proved that mutation of the sumoylation motif in the N-protein leads to cell cycle arrest. 
Work done in our laboratory has shown the inhibition of $\mathrm{S}$ phase progression in cells expressing the N-protein (Surjit et al. 2006). Further, S-phase specific gene products like cyclin $\mathrm{E}$ and CDK2 were found to be downregulated in SARS-CoV infected cell lysate, which suggested that the observed phenomenon may be relevant in vivo. In an attempt to further characterize the mechanism of cell cycle blockage induced by the N-protein, several biochemical and mutational analysis were carried out. Results thus obtained demonstrated that the N-protein directly inhibits the activity of the cyclin-CDK complex, resulting in hypophosphorylation of retinoblastoma protein with a concomitant downregulation of E2F1-mediated transactivation. Analysis of RXL and CDK phosphorylation mutant N-protein identified the mechanisms of inhibition of CDK4 and CDK2 activity to be different. Whereas the N-protein could directly bind to cyclin $\mathrm{D}$ and inhibit the activity of the CDK4-cyclinD complex, inhibition of CDK2 activity appeared to be achieved in two different ways: indirectly by downregulation of protein levels of CDK2, cyclin E, and cyclin A, and by direct binding of N-protein to the CDK2-cyclin complex.

A third piee of evidence supporting the ability of N-protein to deregulate the host cycle came from the work of Zhou et al. (2008). They observed slower transition from $\mathrm{S}$ to $\mathrm{G} 2 / \mathrm{M}$ phase and slower growth rate in N-protein-expressing 293T cells. They also observed a similar phenomenon in human peripheral blood lymphocyte and K 562 cells infected with a retrovirus expressing SARS-CoV N-protein.

\subsubsection{Inhibition of Host Cell Cytokinesis}

While searching for interaction partners for the $\mathrm{C}$ terminus of $\mathrm{N}$-protein (aa 251-422) by following a yeast two-hybrid library screening approach, Zhou et al. (2008) discovered human elongation factor 1 alpha $(\mathrm{EF} 1 \alpha)$ as a candidate partner. The specificity of the interaction was confirmed by various in-vitro and in-vivo assays. Further, expression of N-protein induced aggregation of EF1 $\alpha$. It is known that the majority of cellular EF1 $\alpha$ is bound to F-actin and promotes F-actin bundling, which is a key event during cytokinesis (Kurasawa et al. 1996; Yang et al. 1990). Hence, the authors tested whether N-protein-induced aggregation of EF1 $\alpha$ affected F-actin bundling and cytokinesis. As expected, they observed significantly fewer F-actin bundles in N-protein-expressing cells. In fact, a similar F-actin distribution pattern was also observed by Surjit et al. (2004b) in COS-1 cells. Further, the authors observed multinucleated cells in N-protein-expressing cells at a later time point (72 $\mathrm{h}$ post-transfection), indicating inhibition of cytokinesis in those cells. Specificity of the above data has been confirmed by the use of different deletion mutants of the N-protein, in which only the C-terminal domain of the N-protein (responsible for binding with $\mathrm{EF} 1 \alpha$ ) was able to reproduce the above results. Thus, it has been suggested that EF1 $\alpha$ binding by the N-protein leads to its aggregation, resulting in inhibition of F-actin bundling and subsequent blocking of cytokinesis. 


\subsubsection{Inhibition of Host Cell Translation Machinery}

EF $1 \alpha$ is known to play a key role during the peptide elongation stage of translation. Therefore, it is an attractive candidate for pathogen proteins to manipulate its activity in order to skew the host translation machinery. For example, HIV-type 1 gag polyprotein has been shown to interact with EF1 $\alpha$ and impair translation in vitro (Cimarelli and Luban 1999). Since Zhou et al. (2008) observed an interaction between EF1 $\alpha$ and SARS-CoV N-protein, they further tested whether it interfered with the host translation machinery. Indeed, presence of the N-protein inhibited total cellular translation, both in vitro and in vivo, in a dose-dependent manner. Moreover, exogenous addition of excess EF1 $\alpha$ could reverse the N-proteininduced translation inhibition, thus suggesting that $\mathrm{N}$-protein exerts its effect by interfering with EF1 $\alpha$ function. However, it remains to be confirmed whether a similar effect is recapitulated in vivo.

\subsubsection{Inhibition of Interferon Production}

Production of interferon (IFN) is one of the primary host defense mechanisms. However, SARS-CoV infection does not result in IFN production. Nevertheless, pretreatment of cells with IFN blocks SARS-CoV infection (Spiegel et al. 2005; Zheng et al. 2004). Based on this observation, Palese's laboratory has studied the IFN inhibitory property of different SARS-CoV proteins, which revealed that ORF3, ORF6 as well as the N-protein have the ability to independently inhibit IFN production through different mechanisms. The $\mathrm{N}$-protein was found to inhibit the activity of IRF3 and NFkB in host cells, resulting in inhibition of IFN synthesis. IRF3 activity was also blocked by ORF3, ORF6 proteins, but inhibition of NFkB activity was a property unique to the N-protein. In addition, ORF3, ORF6 proteins were able to block STAT1 activity through different mechanisms (KopeckyBromberg et al. 2007). All these data suggest that SARS-CoV may employ multiple factors to check the activity of the host immune system and N-protein may be one of the major partners in this process. It may be possible that these different factors act independently during different stages of the viral life cycle. In that case, regulatory activity of the N-protein will be as indispensible as its structural activity.

\subsubsection{Modulation of TGF $\beta$ Signaling Pathway}

During the SARS outbreak, a large number of patients developed severe inflammation of the lungs, which subsequently led to acute respiratory distress syndrome (Ding et al. 2003; Nicholls et al. 2003). Acute respiratory distress syndrome is characterized by pulmonary fibrosis, which results in lung failure and subsequent 
death of the patient. The TGF $\beta$ signaling pathway plays a critical role in pulmonary fibrosis (Roberts et al. 2006; Border and Noble 1994). It enhances the expression of extracellular matrix (ECM) proteins, accelerates the secretion of protease inhibitors and reduces the secretion of proteases, thereby leading to deposition of ECM proteins. TGF $\beta$ may also induce pulmonary fibrosis directly by stimulating chemotactic migration and proliferation of fibroblasts as well as by fibroblast-myofibroblast transition. Hence, it is worth speculating that some of the SARS-CoV encoded factors may be modulating the TGF $\beta$ signaling pathway. In fact, proteins of several other viruses, such as hepatitis C virus core, NS3 and NS5 protein, adenovirus E1A, human papilloma virus E7, human T-lymphotropic virus Tax and Epstein-Barr virus LMP1, have been reported to modulate the TGF $\beta$ pathway. In general, these proteins directly bind with smad proteins and alter the innate signaling pathway.

Interestingly, a recent report published by Zhao et al. (2008) revealed that $\mathrm{N}$-protein of SARS-CoV also interacts with $\operatorname{smad} 3$ and modulates the activity of the TGF $\beta$ pathway. By performing a smad binding element (SBE)-driven reporter assay, RT-PCR and immunohistological analysis of TGF $\beta$ target genes such as PAI-1 (plasminogen activator inhibitor 1) and collagen in a variety of cell lines and SARS patients, the authors have clearly proved that N-protein indeed enhanced the activity of the TGF $\beta$ signaling pathway. Further, they observed that the effect of $\mathrm{N}$-protein on TGF $\beta$ signaling was mediated through smad3 only (independent of the involvement of smad4). While trying to unravel the mechanism behind this phenomenon, they observed that N-protein specifically associated with the MH2 domain of smad3 (stronger binding affinity for phospho smad3) interrupted the interaction between smad3 and $\operatorname{smad} 4$, and enhanced the interaction between smad3 and transcriptional coactivator p300 in a dose-dependent manner. To further confirm the above data, they performed a chromatin immunoprecipitation assay at the SBE region of PAI-1 promoter in HPL1 cells and detected the presence of $\mathrm{N}$-protein in the complex of smad3 and p300. Interestingly, however, N-protein inhibited TGF $\beta$-induced apoptosis of HPL1 cells (it is a well established fact that smad3 activation induces apoptosis of HPL1 cells). Thus, N-protein appears to employ a clever mechanism whereby, on the one hand, it enhances the activity of the TGF $\beta$ signaling pathway, thus leading to enhanced expression of a subset of genes (such as ECM protein coding genes), and on the other hand, it blocks the programmed cell death of the host cell. It would be interesting to unravel the mechanism behind this unique property of the N-protein.

\subsubsection{Upregulation of COX2 Production}

Another major proinflammatory factor induced during viral infection is the cyclooxygenase-2 (COX2) protein. Using 293T cells expressing the N-protein, Yan et al. (2006) have shown that expression of the N-protein leads to upregulation of COX2 protein production in a transcriptional manner. They have further demonstrated that the N-protein directly binds to the NFkB response element present in the COX2 
promoter through a 68 aa residue binding domain (aa 136-204) and activates its transcription.

Although the N-protein is known to associate with stretches of nucleic acids, to date there is no other documentation or prediction of its sequence-specific DNA binding activity (as a transcription factor). In such a scenario, the above observation, if reproducible in vivo, may really be a unique property of the N-protein and may further add to the established regulatory functions of the N-protein.

\subsubsection{Upregulation of AP1 Activity}

Exogenously expressed N-protein has been reported to enhance the DNA binding activity of c-fos, ATF-2, CREB-1, and fos B in an ELISA-based assay, thus suggesting an increase in AP1 activity in these cells (He et al. 2003). The mechanistic details and functional significance of this phenomenon remain to be elucidated.

\subsubsection{Induction of Apoptosis}

Earlier work done in our laboratory has shown that N-protein, when expressed in Cos-1 monkey kidney cells, induces apoptosis in the absence of growth factors. Attempts to understand the mechanism of programmed cell death revealed that the $\mathrm{N}$-protein downmodulated the activity of prosurvival factors such as extracellular regulated kinase, Akt and bcl 2, and upregulated the activity of proapoptotic factors like caspase-3 and caspase-7 (Surjit et al. 2004b). However, this phenomenon was not observed in another cell line of epithelial lineage (huh7). The above observation was further confirmed by Zhang et al. (2007). They reported that serum starvationinduced apoptosis of N-protein-expressing COS-1 cells involved activation of mitochondrial pathway. Another elegant study done by Diemer et al. (2008) has further extended our understanding regarding the apoptotic property of the $\mathrm{N}$-protein. Through a series of experiments involving both a model infection system of SARS-CoV and transient transfection of N-protein, the authors have confirmed that $\mathrm{N}$-protein induces an intrinsic apoptotic pathway resulting in activation of caspase-9, which further leads to activation of caspase-3 and -6. Their data further revealed that these activated caspases cleave the N-protein at residues 400 and 403 and that nuclear localization of $\mathrm{N}$-protein is an absolute requirement for cleavage. In addition, the authors have reported that the apoptosis-inducing ability of the $\mathrm{N}$-protein is highly cell type specific. Only in cells where N-protein localizes to both nucleus and cytoplasm (Vero E6 and A549 cells), is it able to activate caspase and become cleaved; however, in cell lines where it localizes to the cytoplasm only (Caco2 and $\mathrm{N}-2 \mathrm{a}$ cells), no activation of caspase is observed. It remains to be studied whether this phenomenon is actually recapitulated in vivo. 


\subsubsection{Upregulation of Prothrombinase (hfgl2) Gene Transcription}

A recent report by Han et al. (2008) revealed that, of all the SARS-CoV structural proteins, only N-protein specifically induced the transcription of prothrombinase gene in THP-1 and Vero cells. By performing luciferase reporter assay of $h f g l 2$ promoter in $\mathrm{N}$-protein-expressing cells and electrophoretic mobility shift assay using $\mathrm{N}$-protein-transfected cell lysate, they demonstrated that $\mathrm{N}$-protein expression induced the binding of transcription factor $\mathrm{C} / \mathrm{EBP} \alpha$ to its cognate response element present in $h f g l 2$ promoter, leading to enhanced transcription of $h f g l 2$ gene. Since lungs of SARS patients have been shown to contain high amount of fibrin, the authors proposed that N-protein-mediated enhanced production of prothrombinase gene may contribute to the development of thrombosis in SARS patients.

\subsubsection{Association with Host Cell Proteins}

Luo et al. (2005) have reported the interaction between hnRNPA1 and N-protein by using a variety of biochemical and genetic assays. The interaction was found to be mediated through the middle region (aa 161-210) of N-protein. If relevant in vivo, this interaction may play a significant role in regulation of the viral RNA synthesis.

Another interesting study done by Luo et al. (2004a) has reported association between the N-protein and human cyclophylin A. By SPR (Surface Plasmn resonance) analysis they have shown it to be a high affinity interaction. Although the significance of this interaction is not known in vivo, they have proposed that this interaction might be crucial for viral infection. Notable is the fact that HIV-1 gag also binds with human cyclophylin $\mathrm{A}$ and this interaction is crucial for HIV infection (Gamble et al. 1996).

Recently, Zeng et al. (2008) have reported that N-protein associates with B23, a phosphoprotein in the nucleus. By performing in vivo coimmunoprecipitation in hela cells and GST pull-down assay using purified recombinant N-protein, the authors have demonstrated direct interaction between B23 and N-protein. The interaction domain has been mapped to amino acid residues 175-210 of N-protein, which include the SR-rich motif. B23 plays a key role in centrosome duplication during cell division. Phosphorylation of B23 at threonine-199 residue is known to regulate its function (Okuda et al. 2000, Tokuyama et al. 2001). In order to demonstrate the functional significance of N-protein interaction with B23 protein, the authors tested the phosphorylation status of threonine-199 residue of B23 in the presence of N-protein. Interestingly, N-protein was able to block threonine-199 phosphorylation. Based on this observation, the authors have proposed that $\mathrm{N}$-protein exerts its effect on cell cycle deregulation by modulating the activity of B23 protein. 
In summary, although several regulatory roles have been proposed for the SARS-CoV N-protein using a variety of in-vitro experimental systems, no clear evidence exists for their occurrence in vivo. In the absence of a suitable in-vivo experimental system, all these functions remain speculative.

\subsection{N-Protein: An Efficient Diagnostic Tool}

One of the most essential steps to limit the outbreak of any infectious disease is the ability to diagnose the causative agent at the earliest possible time, which can be achieved by detecting some of the markers that are specifically expressed by the pathogen or by identifying some of the host factors that are specifically produced during infection. N-protein, being one of the predominantly expressed proteins at the early stage of SARS-CoV infection, against which a strong antibody response is initiated by the host, has been proposed to be an attractive diagnostic tool.

In serum of SARS-CoV patients, the N-protein has been detected as early as day one of infection by ELISA using monoclonal antibodies against it (Che et al. 2004). Further, a comparative study to detect SARS-CoV-specific IgG, SARS-CoV RNA, and the $\mathrm{N}$-protein during early stages of infection has demonstrated that the detection efficiency of the $\mathrm{N}$-protein is significantly higher than the other two markers (Li et al. 2005b).

Researchers have been mainly focussing on two different strategies by which nucleocapsid can be used as a diagnostic tool: (1) development of efficient monoclonal antibodies against the N-protein, and (2) production of recombinantly expressed, highly purified N-protein for detection of N-protein-specific antibody in the host.

Using a phage display approach, Flego et al. (2005) have identified human antibody fragments that recognize distinct epitopes of the $\mathrm{N}$-protein. These may help develop efficient reagents to detect $\mathrm{N}$-protein in the infected host. Further, several laboratories have been trying to develop efficient monoclonal antibodies against the major immunodominant epitopes of the N-protein, that can be used in ELISA to detect SARS-CoV at an early stage of infection (Shang et al. 2005; Liu et al. 2003; He et al. 2005; Woo et al. 2005). In another interesting study, Liu et al. (2005) have developed an immunofluorescence assay using antirabbit N-protein antibody that can specifically detect N-protein from throat wash samples of SARS$\mathrm{CoV}$ patients at day two of illness.

Several other workers have focussed on economical production of highly purified recombinant $\mathrm{N}$-protein using a variety of heterologous expression systems that can be used in ELISA to detect N-protein-specific antibody in the patient sample. $\mathrm{N}$-protein has been produced in abundant quantity using a codon-optimized gene in E. coli (Das and Suresh 2006). Saijo and coworkers have successfully expressed recombinant $\mathrm{N}$-protein using a baculovirus expression system, which was found to be $92 \%$ efficient in neutralizing antibody assay (Saijo et al. 2005). In another study, Liu et al. have expressed full length N-protein using a yeast expression system 
(Liu et al. 2004). However diagnostic use of recombinant N-protein has been a problematic issue because of several reasons as discussed below.

Bacterially expressed N-protein has been reported to produce false seropositivity owing to interference of bacterially derived antigens (Leung et al. 2006; Yip et al 2007). In addition, several studies have shown cross-reactivity between full-length $\mathrm{N}$-protein of SARS and polyclonal antisera of group 1 animal coronaviruses, which may lead to faulty detection (Sun and Meng 2004). Another study done by Woo et al. also reported cross-reactivity of full-length recombinant N-protein with antisera of $\mathrm{HCoV}-\mathrm{OC} 43$ and $\mathrm{HCoV}-229 \mathrm{E}$ infected patients, thus giving false positive results. They were able to minimize this false positivity by further verifying the ELISA results with Western blot assay using recombinant $\mathrm{N}$ and spike proteins of SARS-CoV (Woo et al. 2004).

Later, studies done by Qiu et al. and Bussmann et al. showed that the recombinantly expressed $\mathrm{C}$-terminal of the $\mathrm{N}$-protein acts more specifically in detecting SARS-CoV-specific antisera in comparison to full-length N-protein (Qiu et al. 2005; Bussmann et al. 2006). It is noteworthy that this region is predicted to encompass major antigenic sites of the N-protein.

In a recent report, Shin et al. (2007) demonstrated significantly higher efficacy of phosphorylated N-protein as a diagnostic antigen. They expressed the N-protein in insect cells, where it was phosphorylated by posttranslational modification. When the antigenicity of this protein was compared to that of a bacterially expressed $\mathrm{N}$-protein (unphosphorylated) or to that of a dephosphorylated N-protein (by treatment with protein phosphatase 1) using SARS-positive or -negative patient serum, phosphorylated N-protein did not show any cross-reactivity with SARS-negative serum, thereby reducing the number of false positives. Also, the phosphorylated protein showed considerably stronger cross-reactivity with an N-protein-specific monoclonal antibody. Based on these observations, the authors have proposed the use of a phosphorylated N-protein as a better diagnostic agent.

Also, several reports have been published dealing with the detection of N-protein-specific IgM by ELISA or indirect immunofluorescent assay (Chang et al. 2004; Hsueh et al. 2004; Woo et al. 2004). However, in these studies, IgM antibodies became detectable later than $\mathrm{IgG}$ antibodies, which is in contrast to the phenomena observed in most other pathogens.

A recent report published by Yu et al. (2007) attempted to solve this problem by using a truncated N-protein (aa 122-422) as an antigen in IgM ELISA. They found the IgM response appeared three days before detection of the IgG response, which is in agreement with the results obtained from other known pathogens. Further, their results showed $100 \%$ specificity and sensitivity of the truncated protein in detecting $\mathrm{N}$-protein-specific IgM from patients with laboratory confirmed SARS cases in comparison to healthy volunteers. The authors have suggested that the IgM capture ELISA using this truncated N-protein may be more effective in serodiagnosis of SARS-CoV at an earlier time.

In another interesting report, Woo et al. (2005) carried out comparative studies to evaluate the relative diagnostic efficacy of recombinantly expressed $\mathrm{N}$ and Spike proteins. They observed sensitivity of recombinant N-IgG ELISA to be significantly 
higher than that of recombinant S-IgG ELISA. The reverse was true in the case of IgM ELISA using recombinant $\mathrm{N}$ and $\mathrm{S}$ proteins. Based on this data, they have suggested the practise of ELISA for detection of IgM against both $\mathrm{S}$ and $\mathrm{N}$ proteins instead of $\mathrm{N}$ alone (Woo et al. 2005).

Taken together, all this data does support the notion that the N-protein may be used as an efficient diagnostic tool for detection of SARS-CoV infection. Nevertheless, production scale-up and further validation of specificity using patient samples will determine the possible clinical use of these reagents.

\subsection{N-Protein: A Suitable Vaccine Candidate}

One of the most clinically relevant uses of the N-protein can be its use as a protective vaccine against SARS-CoV infection. N-protein is one of the major antigens of the SARS-CoV. Also, N-protein analyzed from different patient samples shows least variation in the gene sequence (Tong et al. 2004), therefore indicating it to be a stable protein, which is a primary requirement for an efficient vaccine candidate.

Earlier studies carried in Collins', Rao's, and Li's laboratories have clearly shown that antiserum to the N-protein does not contain neutralizing antibodies against SARS-CoV (Buchholz et al. 2004; Pang et al. 2004; Liang et al. 2005). This may be attributed to the localization of $\mathrm{N}$-protein inside the viral envelope, which will not be accessible to the antibody during infection. It is noteworthy that the most effective SARS-CoV structural protein that can induce neutralizing antibody production is the S-protein (Buchholz et al. 2004). The S-protein antibody could block viral infection with $100 \%$ efficiency. On the other hand, although unable to induce humoral immunity, expression of N-protein induced significant cytotoxic T-lymphocyte (CTL) response (Buchholz et al. 2004; Gao et al. 2003; Zhu et al. 2004). Induction of N-protein-specific CTLs will help limit the infection by lysing virus infected cells. This will also limit the spread of virus. Thus, N-protein-based vaccines may further augment the protection efficiency when coadministered with S-protein-based vaccine. Several laboratories have been exploring various strategies to evaluate the potential of $\mathrm{N}$-protein as a vaccine candidate.

In an elegant work done by Kim et al. (2004), calreticulin-fused N-protein expressing vaccinia virus has been shown to generate potent $\mathrm{N}$-protein-specific humoral and T-cell immune responses in mice. As reported by the authors, fusion with calreticulin specifically enhanced the efficiency and significantly reduced the titer of the challenging vector (vaccinia virus). The authors have proposed that $\mathrm{N}$-protein may be the logical choice as a target antigen in the event of S-protein antibody-dependent enhancement (ADE) of infection. However, the ADE phenomenon has not been observed during spike-mediated vaccination (Buchholz et al. 2004). Another study done by Wang et al. (2005) has attempted to use plasmid DNA expressing $\mathrm{S}, \mathrm{M}$, and $\mathrm{N}$ proteins as an efficient vaccine candidate. Although they report the production of some B-cell and T-cell responses against N-protein, 
strong immune response was obtained for the $\mathrm{S}$ and $\mathrm{M}$ proteins, thus scaling down the choice of $\mathrm{N}$-protein as a suitable candidate vaccine (Wang et al. 2005). A similar plasmid-mediated vaccination approach has also been reported by Zhao et al. (2004), in which they immunized mice with the DNA construct (pCI vector) expressing the $\mathrm{N}$-protein. They too reported the generation of a robust B-cell and $\mathrm{T}$-cell immune response in animals. Another group of workers has also reported successful use of the N-protein as a DNA vaccine. They immunized mice by intramucosal injection of the $\mathrm{N}$-protein-expressing plasmid vector and were able to obtain specific humoral and T-cell responses (Zhu et al. 2004).

The N-protein has also been reported to be of potential interest as a peptidebased vaccine. A systematic study done by Liu et al. (2006) has revealed the immunodominant epitopes of the $\mathrm{N}$-protein which could efficiently stimulate immune response. They have also deduced some conserved immunodominant epitopes in mouse, monkey, and humans, which may help in design of the vaccine.

A recent report published by Gao's laboratory provides further evidence regarding the efficiency of an N-protein-based vaccine (Zhao et al. 2007). By using overlapping synthetic peptides spanning the N-protein, they have identified dominant helper T-cell epitopes in the N-protein of SARS-CoV. Immunization of mice with peptides emcompassing these dominant TH cell epitopes resulted in strong cellular immunity in vivo. Priming with the helper peptides significantly accelerated the immune response induced by the N-protein. Further, by fusing with a conserved neutralizing epitope from the spike protein of SARS-CoV, two of the TH cell epitope-bearing peptides assisted in the production of higher titer neutralizing antibodies in vivo, in comparision to spike epitope alone or its mixture with $\mathrm{TH}$ epitope of $\mathrm{N}$. Thus, it is practically possible to generate a better immune response by using a fusion of $\mathrm{N}$ and $\mathrm{S}$ protein. However, the $\mathrm{TH}$ epitopes identified in their report are specific to mouse, and will therefore not be useful for human. Nevertheless, their data provides useful information for the design of peptide-based antiSARS-CoV vaccines.

Another interesting study conducted by Pei et al. (2005) reports the possible use of the N-protein as a mucosal vaccine candidate. They expressed the N-protein in Lactobacillus lactis, which is a food-grade bacteria, and challenged the mice either orally or intramucosally. As preliminary evidence, they were able to observe significant N-protein-specific IgG in the sera of orally challenged animals.

\subsection{Future Perspective}

It is a significant achievement for the research community that, within a short span of time, we have been able to obtain a more-or-less clear understanding regarding the structural and functional properties of the N-protein. However, it is a fact worth mentioning that all the studies done here were performed with in-vitro experiments, using recombinantly expressed N-protein, in isolation. So at present, all we can conclude is that the $\mathrm{N}$-protein per se has the physical ability to perform the above 
described functions, in other words N-protein does bear the necessary signature sequence or motifs or conformation to perform these functions under suitable circumstances. Whether a similar event is recapitulated in vivo during viral infection will be dependent on several criteria: (1) the net effect of other viral factors on the activity of N-protein, (2) the net translation and turnover rate of N-protein, (3) a conducive intracellular milieu, and (4) the net modulation of an already skewed cellular pathway by other viral factors. Hence, it will be interesting to reevaluate the properties of N-protein in a SARS-CoV infection model. However, owing to the limited user-friendliness and accessibility of an infection system, we must probably still resort to in vitro systems for further analysis of the characteristics of $\mathrm{N}$-protein. One of the better experimental systems has already been established by Chang's laboratory (Hsieh et al. 2005), in which all the structural proteins were coexpressed to form VLP in 293T cells. If this system can be further improved to optimize the rate of synthesis of these different proteins to a level near that in vivo, it will at least enable us to study the net effect of the N-protein with respect to other viral proteins. Further establishment of a replicon system may also be helpful. In addition, some of the interesting preliminary observations reported by several laboratories need to be analyzed in detail. To begin with, the reported interaction of the N-protein with the genomic RNA packaging signal needs to be further characterized and mapped. Since the oligomerization domain and the RNA binding regions of the N-protein overlap with each other, the suggested possibility of regulated genome incorporation and capsid assembly should be further characterized with the aid of a replicon system or a particle assembly system. In addition, the reported ability of the N-protein to modulate different cellular pathways should be further characterized in the particle assembly system or at least in the presence of other viral accessory proteins.

The most unique and significant property of the N-protein revealed by preliminary studies is its ability to act as a sequence-specific DNA binding factor. It has been shown to bind the NFkB response element of $C O X 2$ promoter and to enhance COX2 gene expression. This activity may be further empowering the N-protein to manipulate the entire gene expression programme of the infected cell. Therefore, studies should be initiated to analyze this phenomenon in detail. It seems to deserve so much attention because another study done by Palese's laboratory has proved the ability of the N-protein to inhibit NFkB activity, which results in inhibition of IFN synthesis. Further, Liao et al. (2005) have reported the activation of NFkB by N-protein in Vero E6 cells and He et al. (2005) failed to detect any change in NFkB activity in the same cells. Therefore it needs to be clarified whether N-protein enhances NFkB activity and, if so, whether upregulation of COX2 transcription by direct DNA binding is a property specific to that promoter or whether it is a global phenomenon. In such a scenario, there may be complicated cross-talk between the ability of N-protein to deregulate the expression of COX2 and IFN in infected cells.

Lastly, the N-protein is known to be the most abundantly expressed protein of the SARS-CoV. Therefore, any information generated from the analysis of this protein, whether in vivo or ex vivo, will definitely help to increase our understanding 
of the biology of SARS-CoV and may someday help to design better protective tools against it.

Acknowledgments The authors wish to thank Ms. Alisha Lal for helping out in typing and formatting this review. We apologize to all those colleagues whose work we might have omitted to cite in this article.

\section{References}

Border WA, Noble NA (1994) Transforming growth factor beta in tissue fibrosis. N Engl J Med 331:1286-1292

Buchholz UJ, Bukreyev A, Yang L, Lamirande EW, Murphy BR, Subbarao K, Collins PL (2004) Contributions of the structural proteins of severe acute respiratory syndrome coronavirus to protective immunity. Proc Natl Acad Sci USA 101:9804-9809

Bussmann BM, Reiche S, Jacob LH, Braun JM, Jassoy C (2006) Antigenic and cellular localisation analysis of the severe acute respiratory syndrome coronavirus nucleocapsid protein using monoclonal antibodies. Virus Res 122:119-126

Chang WT, Kao CL, Chung MY, Chen SC, Lin SJ, Chiang WC, Chen SY, Su CP, Hsueh PR, Chen WJ, Chen PJ, Yang PC (2004) SARS exposure and emergency department workers. Emerg Infect Dis 10:1117-1119

Chang CK, Sue SC, Yu TH, Hsieh CM, Tsai CK, Chiang YC, Lee SJ, Hsiao HH, Wu WJ, Chang WL, Lin CH, Huang TH (2006) Modular organization of SARS coronavirus nucleocapsid protein. J Biomed Sci 13:59-72

Chang CK, Hsu YL, Chang YH, Chao FA, Wu MC, Huang YS, Hu CK, Huang TH (2008) Multiple nucleic acid binding sites and intrinsic disorder of SARS coronavirus nucleocapsid protein - implication for ribonucleocapsid protein packaging. J Virol 83(5):2255-2264

Che XY, Hao W, Wang Y, Di B, Yin K, Xu YC, Feng CS, Wan ZY, Cheng VC, Yuen KY (2004) Nucleocapsid protein as early diagnostic marker for SARS. Emerg Infect Dis 10:1947-1949

Chen CY, Chang CK, Chang YW, Sue SC, Bai HI, Riang L, Hsiao CD, Huang TH, (2007) Structure of the SARS Coronavirus nucleocapsid protein RNA-binding dimerization domain suggests a mechanism for helical packaging of viral RNA. J Mol Biol 368(4):1075-1086

Cimarelli A, Luban J (1999) Translation elongation factor 1-alpha interacts specifically with the HIV-1 Gag polyprotein. J Virol 73:5388-5401

Das D, Suresh MR (2006) Copious production of SARS-CoV nucleocapsid protein employing codon optimized synthetic gene. J Virol Methods 137:343-346

Diemer C, Schneider M, Seebach J, Quaas J, Frösner G, Schätzl HM, Gilch S (2008) Cell typespecific cleavage of nucleocapsid protein by effector caspases during SARS coronavirus infection. J Mol Biol 376:23-34

Ding Y, Wang H, Shen H, Li Z, Geng J, Han H, Cai J, Li X, Kang W, Weng D, Lu Y, Wu D, He L, Yao K (2003) The clinical pathology of severe acute respiratory syndrome (SARS): a report from China. J Pathol 200:282-289

Fan Z, Zhuo Y, Tan X, Zhou Z, Yuan J, Qiang B, Yan J, Peng X, Gao GF (2006) SARS-CoV nucleocapsid protein binds to hUbc9, a ubiquitin conjugating enzyme of the sumoylation system. J Med Virol 78:1365-1373

Fang X, Ye LB, Zhang Y, Li B, Li S, Kong L, Wang Y, Zheng H, Wang W, Wu Z (2006) Nucleocapsid amino acids 211 to 254 , in particular, tetrad glutamines, are essential for the interaction between the nucleocapsid and membrane proteins of SARS-associated coronavirus. J Microbiol 44:577-580 
Flego M, Di Bonito P, Ascione A, Zamboni S, Carattoli A, Grasso F, Cassone A, Cianfriglia M (2005) Generation of human antibody fragments recognizing distinct epitopes of the nucleocapsid (N) SARS-CoV protein using a phage display approach. BMC Infect Dis 5:73

Gamble TR, Vajdos FF, Yoo S, Worthylake DK, Houseweart M, Sundquist WI, Hill CP (1996) Crystal structure of human cyclophilin A bound to the amino-terminal domain of HIV-1 capsid. Cell 87:1285-1294

Gao W, Tamin A, Soloff A, D'Aiuto L, Nwanegbo E, Robbins PD, Bellini WJ, Barratt-Boyes S, Gambotto A (2003) Effects of a SARS-associated coronavirus vaccine in monkeys. Lancet 362:1895-1896

Han M, Yan W, Huang Y, Yao H, Wang Z, Xi D, Li W, Zhou Y, Hou J, Luo X, Ning Q (2008) The nucleocapsid protein of SARS-CoV induces transcription of hfgl2 prothrombinase gene dependent on C/EBP alpha. J Biochem 144:51-62

He R, Leeson A, Andonov A, Li Y, Bastien N, Cao J, Osiowy C, Dobie F, Cutts T et al (2003) Activation of AP-1 signal transduction pathway by SARS coronavirus nucleocapsid protein. Biochem Biophys Res Commun 311:870-876

He R, Dobie F, Ballantine M, Leeson A, Li Y, Bastien N, Cutts T, Andonov A, Cao J, Booth TF, Plummer FA, Tyler S, Baker L, Xm Li (2004) Analysis of multimerization of the SARS coronavirus nucleocapsid protein. Biochem Biophys Res Commun 316:476-483

He Q, Du Q, Lau S, Manopo I, Lu L, Chan SW, Fenner BJ, Kwang J (2005) Characterization of monoclonal antibody against SARS coronavirus nucleocapsid antigen and development of an antigen capture ELISA. J Virol Methods 127:46-53

Hsieh PK, Chang SC, Huang CC, Lee TT, Hsiao CW, Kou YH, Chen IY, Chang CK, Huang TH, Chang MF (2005) Assembly of severe acute respiratory syndrome coronavirus RNA packaging signal into virus-like particles is nucleocapsid dependent. J Virol 79:13848-13855

Hsueh PR, Huang LM, Chen PJ, Kao CL, Yang PV (2004) Chronological evolution of IgM, IgA, $\mathrm{IgG}$ and neutralisation antibodies after infection with SARS-associated coronavirus. Clin Microbiol Infect 10:1062-1066

Huang Q, Yu L, Petros AM, Gunasekera A, Liu Z, Xu N, Hajduk P, Mack J, Fesik SW, Olejniczak ET (2004) Structure of the N-terminal RNA-binding domain of the SARS CoV nucleocapsid protein. Biochemistry 43:6059-6063

Kim TW, Lee JH, Hung CF, Peng S, Roden R, Wang MC, Viscidi R, Tsai YC, He L, Chen PJ, Boyd DA, Wu TC (2004) Generation and characterization of DNA vaccines targeting the nucleocapsid protein of severe acute respiratory syndrome coronavirus. J Virol 78:4638-4645

Kopecky-Bromberg SA, Martinez-Sobrido L, Frieman M, Baric RA, Palese P (2007) Severe acute respiratory syndrome coronavirus open reading frame (ORF) 3b, ORF 6, and nucleocapsid proteins function as interferon antagonists. J Virol 81:548-557

Krokhin O, Li Y, Andonov A, Feldmann H, Flick R, Jones S, Stroeher U, Bastien N, Dasuri KV, Cheng K, Simonsen JN, Perreault H, Wilkins J, Ens W, Plummer F, Standing KG (2003) Mass spectrometric characterization of proteins from the SARS Virus: a preliminary report. Mol Cell Proteomics 2:346-356

Kurasawa Y, Watanabe Y, Numata O (1996) Characterization of F-actin bundling activity of Tetrahymena elongation factor 1 alpha investigated with rabbit skeletal muscle actin. Zool Sci 13:371-375

Leung DT, van Maren WW, Chan FK, Chan WS, Lo AW, Ma CH, Tam FC, To KF, Chan PK, Sung JJ, Lim PL (2006) Extremely low exposure of a community to severe acute respiratory syndrome coronavirus: false seropositivity due to use of bacterially derived antigens. J Virol 80:8920-8928

Li FQ, Xiao H, Tam JP, Liu DX (2005a) Sumoylation of the nucleocapsid protein of severe acute respiratory syndrome coronavirus. FEBS Lett 579:2387-2396

Li YH, Li J, Liu XE, Wang L, Li T, Zhou YH, Zhuang H (2005b) Detection of the nucleocapsid protein of severe acute respiratory syndrome coronavirus in serum: comparison with results of other viral markers. J Virol Methods 130:45-50 
Liang MF, Du RL, Liu JZ, Li C, Zhang QF, Han LL, Yu JS, Duan SM, Wang XF, Wu KX, Xiong ZH, Jin Q, Li DX (2005) SARS patients-derived human recombinant antibodies to S and $\mathrm{M}$ proteins efficiently neutralize SARS-coronavirus infectivity. Biomed Environ Sci 18:363-374

Liao QJ, Ye LB, Timani KA et al (2005) Activation of NF-kappaB by the full-length nucleocapsid protein of the SARS coronavirus. Acta Biochim Biophys Sin 37:607-612

Liu G, Hu S, Hu Y, Chen P, Yin J, Wen J, Wang J, Lin L, Liu J, You B, Yin Y, Li S, Wang H, Ren Y, Ji J, Zhao X, Sun Y, Zhang X, Fang J, Wang J, Liu S, Yu J, Zhu H, Yang H (2003) The C-terminal portion of the nucleocapsid protein demonstrates SARS-CoV antigenicity. Genomics Proteomics Bioinformatics 1:193-197

Liu RS, Yang KY, Lin J, Lin YW, Zhang ZH, Zhang J, Xia NS (2004) High-yield expression of recombinant SARS coronavirus nucleocapsid protein in methylotrophic yeast Pichia pastoris. World J Gastroenterol 10:3602-3607

Liu IJ, Chen PJ, Yeh SH, Chiang YP, Huang LM, Chang MF, Chen SY, Yang PC, Chang SC, Wang WK (2005) Immunofluorescence assay for detection of the nucleocapsid antigen of the severe acute respiratory syndrome (SARS)-associated coronavirus in cells derived from throat wash samples of patients with SARS. J Clin Microbiol 43:2444-2448

Liu SJ, Leng CH, Lien SP, Chi HY, Huang CY, Lin CL, Lian WC, Chen CJ, Hsieh SL, Chong P (2006) Immunological characterizations of the nucleocapsid protein based SARS vaccine candidates. Vaccine 24:3100-3108

Luo C, Luo H, Zheng S, Gui C, Yue L, Yu C, Sun T, He P, Chen J, Shen J, Luo X, Li Y, Liu H, Bai D, Shen J, Yang Y, Li F, Zuo J, Hilgenfeld R, Pei G, Chen K, Shen X, Jiang H (2004a) Nucleocapsid protein of SARS coronavirus tightly binds to human cyclophilin A. Biochem Biophys Res Commun 321:557-565

Luo H, Ye F, Sun T, Yue L, Peng S, Chen J, Li G, Du Y, Xie Y, Yang Y, Shen J, Wang Y, Shen X, Jiang H (2004b) In vitro biochemical and thermodynamic characterization of nucleocapsid protein of SARS. Biophys Chem 112:15-25

Luo H, Chen Q, Chen J, Chen K, Shen X, Jiang H (2005) The nucleocapsid protein of SARS coronavirus has a high binding affinity to the human cellular heterogeneous nuclear ribonucleoprotein A1. FEBS Lett 579:2623-2628

Luo H, Chen J, Chen K, Shen X, Jiang H (2006) Carboxyl terminus of severe acute respiratory syndrome coronavirus nucleocapsid protein: self-association analysis and nucleic acid binding characterization. Biochemistry 45:11827-11835

Nicholls JM, Poon LL, Lee KC, Ng WF, Lai ST, Leung CY, Chu CM, Hui PK, Mak KL, Lim W, Yan KW, Chan KH, Tsang NC, Guan Y, Yuen KY, Peiris JS (2003) Lung pathology of fatal severe acute respiratory syndrome. Lancet 361:1773-1778

Okuda M, Horn HF, Tarapore P, Tokuyama Y, Smulian AG, Chan PK, Knudsen ES, Hofmann IA, Snyder JD, Bove KE, Fukasawa K (2000) Nucleophosmin/B23 is a target of CDK2/cyclin E in centrosome duplication. Cell 103:127-140

Pang H, Liu Y, Han X, Xu Y, Jiang F, Wu D, Kong X, Bartlam M, Rao Z (2004) Protective humoral responses to severe acute respiratory syndrome-associated coronavirus: implications for the design of an effective protein-based vaccine. J Gen Virol 85:3109-3113

Pei H, Liu J, Cheng Y, Sun C, Wang C, Lu Y, Ding J, Zhou J, Xiang H (2005) Expression of SARS-coronavirus nucleocapsid protein in Escherichia coli and Lactococcus lactis for serodiagnosis and mucosal vaccination. Appl Microbiol Biotechnol 68:220-227

Qiu M, Wang J, Wang H, Chen Z, Dai E, Guo Z, Wang X, Pang X, Fan B, Wen J, Wang J, Yang R (2005) Use of the $\mathrm{COOH}$ portion of the nucleocapsid protein in an antigen-capturing enzymelinked immunosorbent assay for specific and sensitive detection of severe acute respiratory syndrome coronavirus. Clin Diagn Lab Immunol 12:474-476

Roberts AB, Tian F, Byfield SD, Stuelten C, Ooshima A, Saika S, Flanders KC (2006) Smad3 is key to TGF-beta-mediated epithelial-to-mesenchymal transition, fibrosis, tumor suppression and metastasis. Cytokine Growth Factor Rev 17:19-27 
Rota PA, Oberste MS, Monroe SS, Nix WA, Campagnoli R, Icenogle JP, Penaranda S, Bankamp B, Maher K, Chen MH, Tong S, Tamin A, Lowe L, Frace M, DeRisi JL, Chen Q, Wang D, Erdman DD, Peret TC, Burns C, Ksiazek TG, Rollin PE, Sanchez A, Liffick S, Holloway B, Limor J, McCaustland K, Olsen-Rasmussen M, Fouchier R, Gunther S, Osterhaus AD, Drosten C, Pallansch MA, Anderson LJ, Bellini WJ (2003) Characterization of a novel coronavirus associated with severe acute respiratory syndrome. Science 300: 1394-1399

Rowland RR, Chauhan V, Fang Y, Pekosz A, Kerrigan M, Burton MD (2005) Intracellular localization of the severe acute respiratory syndrome coronavirus nucleocapsid protein: absence of nucleolar accumulation during infection and after expression as a recombinant protein in vero cells. J Virol 79:11507-11512

Saijo M, Ogino T, Taguchi F, Fukushi S, Mizutani T, Notomi T, Kanda H, Minekawa H, Matsuyama S, Long HT, Hanh NT, Kurane I, Tashiro M, Morikawa S (2005) Recombinant nucleocapsid protein-based IgG enzyme-linked immunosorbent assay for the serological diagnosis of SARS. J Virol Methods 125:181-186

Shang B, Wang XY, Yuan JW, Vabret A, Wu XD, Yang RF, Tian L, Ji YY, Deubel V, Sun B (2005) Characterization and application of monoclonal antibodies against N protein of SARScoronavirus. Biochem Biophys Res Commun 336:110-117

Shin GC, Chung YS, Kim IS, Cho HW, Kang C (2007) Antigenic characterization of severe acute respiratory syndrome-coronavirus nucleocapsid protein expressed in insect cells: The effect of phosphorlation on immunoreactivity and specificity. Virus Res 127:71-80

Spiegel M, Pichlmair A, Martinez-Sobrido L, Cros J, Garcia-Sastre A, Haller O, Weber F (2005) Inhibition of beta interferon induction by severe acute respiratory syndrome coronavirus suggests a two-step model for activation of interferon regulatory factor 3. J Virol 79: 2079-2086

Sun ZF, Meng XJ (2004) Antigenic cross-reactivity between the nucleocapsid protein of severe acute respiratory syndrome (SARS) coronavirus and polyclonal antisera of antigenic group I animal coronaviruses: implication for SARS diagnosis. J Clin Microbiol. 42: 2351-2352

Surjit M, Liu B, Kumar P, Chow VT, Lal SK (2004a) The nucleocapsid protein of the SARS coronavirus is capable of self-association through a C-terminal 209 amino acid interaction domain. Biochem Biophys Res Commun 317:1030-1036

Surjit M, Liu B, Jameel S, Chow VT, Lal SK (2004b) The SARS coronavirus nucleocapsid protein induces actin reorganization and apoptosis in COS-1 cells in the absence of growth factors. Biochem J 383:13-18

Surjit M, Kumar R, Mishra RN, Reddy MK, Chow VT, Lal SK (2005) The severe acute respiratory syndrome coronavirus nucleocapsid protein is phosphorylated and localizes in the cytoplasm by 14-3-3-mediated translocation. J Virol 79:11476-11486

Surjit M, Liu B, Chow VT, Lal SK (2006) The nucleocapsid protein of severe acute respiratory syndrome-coronavirus inhibits the activity of cyclin-cyclin-dependent kinase complex and blocks S phase progression in mammalian cells. J Biol Chem 281:10669-10681

Timani KA, Liao Q, Ye L, Zeng Y, Liu J, Zheng Y, Ye L, Yang X, Lingbao K, Gao J, Zhu Y (2005) Nuclear/nucleolar localization properties of C-terminal nucleocapsid protein of SARS coronavirus. Virus Res 114:23-34

Tokuyama Y, Horn HF, Kawamura K, Tarapore P, Fukasawa K (2001) Specific phosphorylation of nucleophosmin on $\operatorname{Thr}(199)$ by cyclin-dependent kinase 2-cyclin E and its role in centrosome duplication. J Biol Chem 276:21529-21537

Tong S, Lingappa JR, Chen Q, Shu B, LaMonte AC, Cook BT, Birge C, Chern SW, Liu X, Galloway R, le Mai Q, Ng WF, Yang JY, Butany J, Comer JA, Monroe SS, Beard SR, Ksiazek TG, Erdman D, Rota PA, Pallansch MA, Anderson LJ (2004) Direct sequencing of SARScoronavirus $\mathrm{S}$ and $\mathrm{N}$ genes from clinical specimens shows limited variation. $\mathrm{J}$ Infect Dis 190:1127-1131

Wang Y, Wu X, Wang Y, Li B, Zhou H, Yuan G, Fu Y, Luo Y (2004) Low stability of nucleocapsid protein in SARS virus. Biochemistry 43:11103-11108 
Wang Z, Yuan Z, Matsumoto M, Hengge UR, Chang YF (2005) Immune responses with DNA vaccines encoded different gene fragments of severe acute respiratory syndrome coronavirus in BALB/c mice. Biochem Biophys Res Commun 327:130-135

Woo PCY, Lau SKP, Wong BHL, Chan KH, Chu CM, Tsoi HW, Huang Y, Peiris JSM, Yuen KY (2004) Longitudinal profile of immunoglobulin $\mathrm{G}$ ( $\operatorname{IgG}), \operatorname{IgM}$, and $\operatorname{IgA}$ antibodies against the severe acute respiratory syndrome (SARS) coronavirus nucleocapsid protein in patients with pneumonia due to the SARS coronavirus. Clin Diagn Lab Immunol 11:665-668

Woo PC, Lau SK, Wong BH, Tsoi HW, Fung AM, Kao RY, Chan KH, Peiris JS, Yuen KY (2005) Differential sensitivities of severe acute respiratory syndrome (SARS) coronavirus spike polypeptide enzyme-linked immunosorbent assay (ELISA) and SARS coronavirus nucleocapsid protein ELISA for serodiagnosis of SARS coronavirus pneumonia. J Clin Microbiol 43:3054-3058

Wu CH, Yeh SH, Tsay YG, Shieh YH, Kao CL, Chen YS, Wang SH, Kuo TJ, Chen DS, Chen PJ (2008) Glycogen synthase kinase-3 regulates the phosphorylation of sars-coronavirus nucleocapsid protein and viral replication. J Biol Chem 284(8):5229-5239

Yan X, Hao Q, Mu Y, Timani KA, Ye L, Zhu Y, Wu J (2006) Nucleocapsid protein of SARS-CoV activates the expression of cyclooxygenase- 2 by binding directly to regulatory elements for nuclear factor-kappa B and CCAAT/enhancer binding protein. Int J Biochem Cell Biol 38:1417-1428

Yang F, Demma M, Warren V, Dharmawardhane S, Condeelis J (1990) Identification of an actinbinding protein from Dictyostelium as elongation factor 1a. Nature 347:494-496

Yip CW, Hon CC, Zeng F, Chow KY, Chan KH, Peiris JS, Leung FC (2007) Naturally occurring anti-Escherichia coli protein antibodies in the sera of healthy humans cause analytical interference in a recombinant nucleocapsid protein-based enzyme-linked immunosorbent assay for serodiagnosis of severe acute respiratory syndrome. Clin Vaccine Immunol 14:99-101

You J, Dove BK, Enjuanes L, DeDiego ML, Alvarez E, Howell G, Heinen P, Zambon M, Hiscox JA (2005) Subcellular localization of the severe acute respiratory syndrome coronavirus nucleocapsid protein. J Gen Virol 86:3303-3310

Yu IM, Gustafson CL, Diao J, Burgner JW 2nd, Li Z, Zhang J, Chen J (2005) Recombinant severe acute respiratory syndrome (SARS) coronavirus nucleocapsid protein forms a dimer through its C-terminal domain. J Biol Chem 280:23280-23286

Yu IM, Oldham ML, Zhang J, Chen J (2006) Crystal structure of the severe acute respiratory syndrome (SARS) coronavirus nucleocapsid protein dimerization domain reveals evolutionary linkage between corona- and arteriviridae. J Biol Chem 281:17134-17139

Yu F, Le MQ, Inoue S, Hasebe F, Parquet Mdel C, Morikawa S, Morita K (2007) Recombinant truncated nucleocapsid protein as antigen in a novel immunoglobulin $\mathrm{M}$ capture enzymelinked immunosorbent assay for diagnosis of severe acute respiratory syndrome coronavirus infection. Clin Vaccine Immunol 14:146-149

Zakhartchouk AN, Viswanathan S, Mahony JB, Gauldie J, Babiuk LA (2005) Severe acute respiratory syndrome coronavirus nucleocapsid protein expressed by an adenovirus vector is phosphorylated and immunogenic in mice. J Gen Virol 86:211-215

Zeng Y, Ye L, Zhu S, Zheng H, Zhao P, Cai W, Su L, She Y, Wu Z (2008) The nucleocapsid protein of SARS-associated coronavirus inhibits B23 phosphorylation. Biochem Biophys Res Commun 369:287-291

Zhang L, Wei L, Jiang D, Wang J, Cong X, Fei R (2007) SARS-CoV nucleocapsid protein induced apoptosis of COS-1 mediated by the mitochondrial pathway. Artif Cells Blood Substit Immobil Biotechnol 35:237-253

Zhao P, Cao J, Zhao LJ, Qin ZL, Ke JS, Pan W, Ren H, Yu JG, Qi ZT (2004) Immune responses against SARS-coronavirus nucleocapsid protein induced by DNA vaccine. Virology 331: $128-135$

Zhao J, Huang Q, Wang W, Zhang Y, Lv P, Gao XM (2007) Identification and characterization of dominant helper $\mathrm{T}$-cell epitopes in the nucleocapsid protein of severe acute respiratory syndrome coronavirus. J Virol 81:6079-6088 
Zhao X, Nicholls JM, Chen YG (2008) Severe acute respiratory syndrome-associated coronavirus nucleocapsid protein interacts with $\mathrm{Smad} 3$ and modulates transforming growth factor-beta signaling. J Biol Chem 283:3272-3280

Zheng B, He ML, Wong KL, Lum CT, Poon LL, Peng Y, Guan Y, Lin MC, Kung HF (2004) Potent inhibition of SARS-associated coronavirus (SCOV) infection and replication by type I interferons (IFNalpha/ beta) but not by type II interferon (IFN-gamma). J Interferon Cytokine Res 24:388-390

Zhou B, Liu J, Wang Q, Liu X, Li X, Li P, Ma Q, Cao C (2008) The nucleocapsid protein of severe acute respiratory syndrome coronavirus inhibits cell cytokinesis and proliferation by interacting with translation elongation factor 1alpha. J Virol 82:6962-6971

Zhu MS, Pan Y, Chen HQ, Shen Y, Wang XC, Sun YJ, Tao KH (2004) Induction of SARSnucleoprotein-specific immune response by use of DNA vaccine. Immunol Lett 92:237-243 